\title{
Practice Patterns and Outcomes Among Patients With NOMO Prostate Cancer and a Very High Prostate-Specific Antigen Level
}

\author{
Vinayak Muralidhar, MD, MSca; Paul L. Nguyen, MD ${ }^{\mathrm{b}}$; Brandon A. Mahal, MDa; David D. Yang, MDa; \\ Kent W. Mouw, MD, PhD'; Brent S. Rose, MDc; Clair J. Beard, MD'; Jason A. Efstathiou, MD, DPhild; \\ Neil E. Martin, MD, MPH ${ }^{b}$; Martin T. King, MD, $\mathrm{PhD}^{\mathrm{b}, \star}$; and Peter F. Orio III, DO, MS
}

\begin{abstract}
Background: Management of patients with a very high prostatespecific antigen (PSA) level ( $\geq 98.0 \mathrm{ng} / \mathrm{mL}$ ) but clinically localized (NOMO) prostate cancer is challenging. This study sought to determine practice patterns and outcomes among these patients. Patients and Methods: A total of 748,825 patients with prostate cancer from 2004 through 2012 were identified using the National Cancer Database. These patients were subdivided by PSA level (0-9.9, 10.0-19.9, 20.0-39.9, 40.0-59.9, 60.0-79.9, 80.0-97.9, and $\geq 98.0 \mathrm{ng} / \mathrm{mL}$ ), nodal status (N0 vs N1), and distant metastases (M0 vs M1). Rates of locoregional treatment and 5-year overall survival (OS) in each group were determined. Survival was compared using Cox regression after adjusting for multiple patient-specific factors. Results: The rate of locoregional treatment for patients with NOMO disease and PSA level $\geq 98.0 \mathrm{ng} / \mathrm{mL}$ was significantly lower than for those with $\mathrm{N} 1 \mathrm{M} 0$ disease $(52.6 \%$ vs $60.4 \% ; P<.001)$ or NOM0 disease and PSA level $<98.0 \mathrm{ng} / \mathrm{mL}$ ( $52.6 \%$ vs $86.6 \% ; P<.001)$. The 5 -year OS rate was similar for patients with $\mathrm{N} 1 \mathrm{M} 0$ disease and those with NOMO disease and a very high PSA level (63.2\% vs $59.1 \%$; adjusted hazard ratio [aHR], $0.91 ; P=.063$ ). The survival benefit associated with locoregional treatment was higher among those with NOMO disease and a very high PSA level than among those with N1M0 disease (aHR, 0.28 vs $0.44 ; P<.001)$. Conclusions: Patients with clinical NOMO disease and a very high PSA level $(\geq 98.0 \mathrm{ng} / \mathrm{mL})$ have outcomes similar to those with N1 disease but receive locoregional treatment at a lower rate. Future work is needed to investigate the utility of locoregional treatment in this population.
\end{abstract}

J Natl Compr Canc Netw 2019;17(8):941-948 doi: $10.6004 /$ jnccn.2018.7283

\footnotetext{
aHarvard Radiation Oncology Program, Harvard Medical School, and bDepartment of Radiation Oncology, Brigham and Women's Hospital/ Dana-Farber Cancer Institute, Boston, Massachusetts; 'Department of Radiation Oncology, University of California at San Diego, La Jolla, California; and dDepartment of Radiation Oncology, Massachusetts General Hospital, Boston, Massachusetts.
}

*These authors contributed equally.

\section{Background}

Initial treatment of prostate cancer is driven by clinical risk factors, including $\mathrm{T}$ stage, Gleason score, and prostatespecific antigen (PSA) level, in addition to assessment of regional nodal or distant spread. ${ }^{1}$ In men with unfavorable localized disease and sufficient life expectancy to warrant definitive treatment, several randomized trials have established radical prostatectomy or radiation therapy, with or without hormonal therapy, to be a standard of care. $^{2-6}$ For metastatic disease, systemic therapy alone is recommended, with palliative radiation given in some cases. ${ }^{1}$ For patients with a very high PSA level $(\geq 98.0 \mathrm{ng} / \mathrm{mL})$ but no clinical evidence of lymph node or distant involvement, clinicians may be uncertain of the optimal treatment framework. Technically, these patients have localized high-risk prostate cancer for which curative locoregional treatment is typically indicated, but the presence of a very high PSA level may raise concern for occult metastatic disease, which would not be considered curable with locoregional treatment.

We used data from a large national database of patients with prostate cancer to determine patterns of care among patients with NOM0 disease and a very high PSA level, specifically focused on receipt of locoregional treatment, compared with others with N0M0 disease, node-positive disease, or metastatic disease. We also studied survival outcomes among these various subgroups of patients and explored the possible survival benefit associated with locoregional treatment.

\section{Patients and Methods}

\section{Patient Population}

The National Cancer Database (NCDB) captures approximately $70 \%$ of newly diagnosed cancer cases in the United States. ${ }^{7}$ We used the NCDB to identify 748,625 patients with prostate cancer diagnosed from 2004 through 2012. Patients were included if they were diagnosed with prostate adenocarcinoma and had complete data available regarding the staging of regional nodal or distant metastatic disease and PSA level. Patients were excluded if 
they were listed as having $\mathrm{Nx}$ or Mx disease; because of limitations in the NCDB, data were unavailable on exactly how patients were staged (eg, CT, bone scan). This project was approved by the Dana-Farber Cancer Institute Institutional Review Board.

\section{Statistical Analyses}

All statistical analyses were performed using STATA/MP 15.0 (StataCorp LLP). Patients were subdivided by serum PSA level at diagnosis (0-9.9, 10.0-19.9, 20.0-39.9, $40.0-59.9,60.0-79.9,80.0-97.9$, and $\geq 98.0 \mathrm{ng} / \mathrm{mL}$ ), nodal status (N0 vs N1), and presence of distant metastases (M0 vs M1). Presence of nodal or distant metastases is recorded in the NCDB before treatment based on coding from patient medical records. The PSA cutoff of $\geq 98.0 \mathrm{ng} / \mathrm{mL}$ was chosen due to limitations in the NCDB: all PSA levels $\geq 98.0 \mathrm{ng} / \mathrm{mL}$ are grouped together without further granularity regarding the exact PSA level.

Median age and follow-up were compared using the Kruskal-Wallis test; other baseline patient characteristics were compared using the chi-square test. We determined the rate of definitive locoregional treatment (pelvic or prostate radiation or radical prostatectomy) or androgen deprivation therapy (ADT) in each group. Rates of locoregional treatment or ADT were compared using multivariable logistic regression, adjusting for patient race, income quartile, education quartile, age, Charlson/ Deyo comorbidity score ( 0 vs 1 vs $\geq 2$ ), insurance status, residence type (urban vs rural), year of diagnosis, T stage, and receipt of ADT. Income and education quartiles were defined by matching a patient's US ZIP code to data from the 2000 US Census. Patient income quartiles corresponded to the following yearly incomes: (1) $<\$ 30,000$, (2) $\$ 30,000$ to $\$ 34,999$, (3) $\$ 35,000$ to $\$ 45,999$, and (4) $>\$ 46,000$. Education quartiles corresponded to the percentage of adults aged $>25$ years without a high school diploma: (1) $\geq 29.0 \%$, (2) $20.0 \%$ to $28.9 \%$, (3) $14.0 \%$ to $19.9 \%$, and (4) $<14.0 \%$. Because of limitations in the NCDB related to differential coding of tumor grade among patients treated with versus without radical prostatectomy, we did not adjust for Gleason score.

Overall survival (OS) at 5 years in each group was determined using the Kaplan-Meier method. Survival was compared between groups using multivariable Cox regression modeling after adjusting for the same factors listed in the previous paragraph. The effect of locoregional treatment on OS was tested similarly using Cox multivariable regression modeling within each group, and the differential effect of locoregional treatment between patients with very-high-PSA NOM0 disease and those with N1M0 disease was tested by generating an interaction term between receipt of locoregional treatment and whether patients had veryhigh-PSA N0M0 disease versus N1M0 disease. All reported $P$ values were 2 -sided and deemed significant at $\alpha=0.05$.

\section{Results}

\section{Baseline Characteristics}

Patient baseline characteristics are shown in Table 1. A total of 3,142 patients had N0M0 disease with a PSA level $\geq 98.0 \mathrm{ng} / \mathrm{mL}$. Median follow-up among all patients was 3.9 years. Patients with PSA $\geq 98.0 \mathrm{ng} / \mathrm{mL}$, NOM0 disease tended to be older, and have a higher $\mathrm{T}$ stage at diagnosis compared with those with PSA $<98.0 \mathrm{ng} / \mathrm{mL}$ N0M0 disease $(P<.001$ in all cases). Patients with node-positive (N1) or distant metastatic (M1) disease also tended to have higher $\mathrm{T}$ stages at diagnosis compared with those with clinically localized disease with PSA $<98.0 \mathrm{ng} / \mathrm{mL}$.

\section{Rates of Locoregional Treatment}

The rate of definitive locoregional treatment for patients with PSA $\geq 98.0 \mathrm{ng} / \mathrm{mL}$ N0M0 disease was $52.6 \%$, which was significantly lower than among those with PSA $<98.0 \mathrm{ng} / \mathrm{mL}$ N0M0 disease $(86.6 \% ; P<.001)$ (Figure 1 ). Among patients with clinical N0M0 disease with PSA levels of 0.0 to $9.9,10.0$ to $19.9,20.0$ to $39.9,40.0$ to 59.9 , 60.0 to 79.9 , and 80.0 to $97.9 \mathrm{ng} / \mathrm{mL}$, the rates of definitive locoregional treatment were $87.8 \%, 83.9 \%, 79.6 \%$, $81.0 \%, 78.7 \%$, and $75.6 \%$, respectively (Figure 1 ). The rate of locoregional treatment for patients with very-high-PSA N0M0 disease was also significantly lower than for those with N1M0 disease (52.6\% vs $60.4 \% ; P<.001$ ), whereas the rate among those with $\mathrm{Ml}$ disease was significantly lower than all other subgroups $(10.6 \% ; P<.001)$.

\section{Rates of ADT Monotherapy}

Patients with very-high-PSA NOM0 disease were much more likely to receive ADT monotherapy compared with others with N0M0 disease $(28.2 \%$ vs $2.69 \% ; P<.001)$, with similar rates as those with N1M0 disease $(28.1 \% ; P=.218)$. Patients with $\mathrm{Ml}$ disease were more likely to receive ADT monotherapy than all other patient subgroups (63.4\%; $P<.001)$.

\section{Overall Survival by PSA and Disease Stage}

Among patients with clinically localized disease (NOM0), the 5-year OS rate decreased with increasing PSA levels $(91.6 \%, 84.3 \%, 80.2 \%, 84.1 \%, 81.8 \%, 80.2 \%$, and $59.1 \%$ for PSA levels of 0.0-9.9, 10.0-19.9, 20.0-39.9, 40.0-59.9, $60.0-79.9,80.0-97.9$, and $\geq 98.0 \mathrm{ng} / \mathrm{mL}$, respectively; Figure 2A). For men with N1M0 disease, the 5-year OS rate was $63.2 \%$, which was not significantly different compared with those with PSA $\geq 98.0 \mathrm{ng} / \mathrm{mL}$ N0M0 disease (adjusted hazard ratio [aHR], 0.91; 95\% CI, 0.83-1.00; $P=.063$; Figure 2B). Patients with M1 disease had a 5-year 


\section{Table 1. Patient Baseline Characteristics}

PSA $<98.0 \mathrm{ng} / \mathrm{mL}$, NOMO $(N=720,764)$

PSA $\geq 98.0 \mathrm{ng} / \mathrm{mL}$,

NOMO $(\mathrm{N}=3,142)$

\section{Patient Characteristic}

n

$\%$

n $\%$

N1MO $(\mathrm{N}=6,588)$

MI $(\mathrm{N}=18, \mathbf{3 3 1})$

\begin{tabular}{|c|c|c|c|c|c|c|c|c|c|}
\hline Median follow-up, years (IQR), y & $4.0(2.3-5.9)$ & & $2.8(1.7-4.6)$ & & $3.3(1.9-5.3)$ & & $1.6(0.6-3.1)$ & & $<.001$ \\
\hline Race & & & & & & & & & $<.001$ \\
\hline White & 590,771 & $82.0 \%$ & 2,054 & $65.4 \%$ & 5,258 & $79.8 \%$ & 13,761 & $75.1 \%$ & \\
\hline Black & 98,582 & $13.7 \%$ & 930 & $29.6 \%$ & 1,033 & $15.7 \%$ & 3,794 & $20.7 \%$ & \\
\hline Other & 19,307 & $2.7 \%$ & 116 & $3.7 \%$ & 179 & $2.7 \%$ & 554 & $3.0 \%$ & \\
\hline Unknown & 12,104 & $1.7 \%$ & 42 & $1.3 \%$ & 118 & $1.8 \%$ & 222 & $1.2 \%$ & \\
\hline Household income & & & & & & & & & $<.001$ \\
\hline$\geq \$ 46,000$ & 306,035 & $42.5 \%$ & 926 & $29.5 \%$ & 2,624 & $39.8 \%$ & 6,260 & $34.1 \%$ & \\
\hline$\$ 35,000-\$ 45,999$ & 187,208 & $26.0 \%$ & 824 & $26.2 \%$ & 1,703 & $25.9 \%$ & 4,884 & $26.6 \%$ & \\
\hline$\$ 30,000-\$ 34,999$ & 115,170 & $16.0 \%$ & 593 & $18.9 \%$ & 1,074 & $16.3 \%$ & 3,263 & $17.8 \%$ & \\
\hline$<\$ 30,000$ & 83,624 & $11.6 \%$ & 676 & $21.5 \%$ & 894 & $13.6 \%$ & 3,157 & $17.2 \%$ & \\
\hline Unknown & 28,727 & $4.0 \%$ & 123 & $3.9 \%$ & 293 & $4.4 \%$ & 767 & $4.2 \%$ & \\
\hline Percent not graduating high school & & & & & & & & & $<.001$ \\
\hline$<14.0 \%$ & 279,498 & $38.8 \%$ & 836 & $26.6 \%$ & 2,401 & $36.4 \%$ & 5,508 & $30.0 \%$ & \\
\hline $14.0-19.9 \%$ & 163,194 & $22.6 \%$ & 659 & $21.0 \%$ & 1,504 & $22.8 \%$ & 3,947 & $21.5 \%$ & \\
\hline $20.0-28.9 \%$ & 148,457 & $20.6 \%$ & 716 & $22.8 \%$ & 1,293 & $19.6 \%$ & 4,278 & $23.3 \%$ & \\
\hline$\geq 29 \%$ & 100,814 & $14.0 \%$ & 806 & $25.7 \%$ & 1,096 & $16.6 \%$ & 3,830 & $20.9 \%$ & \\
\hline Unknown & 28,801 & $4.0 \%$ & 125 & $4.0 \%$ & 294 & $4.5 \%$ & 768 & $4.2 \%$ & \\
\hline Age & & & & & & & & & $<.001$ \\
\hline$\leq 66 y$ & 408,329 & $56.7 \%$ & 1,341 & $42.7 \%$ & 3,516 & $53.4 \%$ & 6,396 & $34.9 \%$ & \\
\hline$>66 y$ & 312,435 & $43.3 \%$ & 1,801 & $57.3 \%$ & 3,072 & $46.6 \%$ & 11,935 & $65.1 \%$ & \\
\hline Year of diagnosis & & & & & & & & & $<.001$ \\
\hline 2004-2007 & 286,934 & $39.8 \%$ & 962 & $30.6 \%$ & 2,577 & $39.1 \%$ & 8,200 & $44.7 \%$ & \\
\hline $2008-2012$ & 433,830 & $60.2 \%$ & 2,180 & $69.4 \%$ & 4,011 & $60.9 \%$ & 10,131 & $55.3 \%$ & \\
\hline Charlson/Deyo comorbidity score & & & & & & & & & $<.001$ \\
\hline 0 & 615,790 & $85.4 \%$ & 2,570 & $81.8 \%$ & 5,523 & $83.8 \%$ & 14,265 & $77.8 \%$ & \\
\hline 1 & 90,140 & $12.5 \%$ & 439 & $14.0 \%$ & 851 & $12.9 \%$ & 2,793 & $15.2 \%$ & \\
\hline$\geq 2$ & 14,834 & $2.1 \%$ & 133 & $4.2 \%$ & 214 & $3.2 \%$ & 1,273 & $6.9 \%$ & \\
\hline Insurance & & & & & & & & & $<.001$ \\
\hline Not insured & 10,840 & $1.5 \%$ & 174 & $5.5 \%$ & 267 & $4.1 \%$ & 1,018 & $5.6 \%$ & \\
\hline Private insurance & 344,680 & $47.8 \%$ & 931 & $29.6 \%$ & 2,704 & $41.0 \%$ & 4,401 & $24.0 \%$ & \\
\hline Medicaid & 14,998 & $2.1 \%$ & 195 & $6.2 \%$ & 263 & $4.0 \%$ & 1,158 & $6.3 \%$ & \\
\hline Medicare & 327,389 & $45.4 \%$ & 1,712 & $54.5 \%$ & 3,072 & $46.6 \%$ & 11,055 & $60.3 \%$ & \\
\hline Other government & 11,902 & $1.7 \%$ & 52 & $1.7 \%$ & 91 & $1.4 \%$ & 191 & $1.0 \%$ & \\
\hline Unknown & 10,955 & $1.5 \%$ & 78 & $2.5 \%$ & 191 & $2.9 \%$ & 508 & $2.8 \%$ & \\
\hline Residence type & & & & & & & & & .147 \\
\hline Urban & 682,325 & $94.7 \%$ & 2,975 & $94.7 \%$ & 6,231 & $94.6 \%$ & 17,279 & $94.3 \%$ & \\
\hline Rural & 14,463 & $2.0 \%$ & 75 & $2.4 \%$ & 121 & $1.8 \%$ & 337 & $1.8 \%$ & \\
\hline Unknown & 23,976 & $3.3 \%$ & 92 & $2.9 \%$ & 236 & $3.6 \%$ & 715 & $3.9 \%$ & \\
\hline
\end{tabular}

Abbreviations: ADT, androgen deprivation therapy; IQR, interquartile range; PSA, prostate-specific antigen. 


\section{Table 1. Patient Baseline Characteristics (cont.)}

\begin{tabular}{|c|c|c|c|c|c|c|c|c|c|}
\hline \multirow[b]{2}{*}{ Patient Characteristic } & \multicolumn{2}{|c|}{$\begin{array}{l}\text { PSA < } 98.0 \mathrm{ng} / \mathrm{mL} \text {, } \\
\text { NOMO }(\mathrm{N}=720,764)\end{array}$} & \multicolumn{2}{|c|}{$\begin{array}{l}\text { PSA } \geq 98.0 \mathrm{ng} / \mathrm{mL}, \\
\text { NOMO }(\mathrm{N}=3,142)\end{array}$} & \multicolumn{2}{|c|}{$\mathrm{N} 1 \mathrm{M0}(\mathrm{N}=6,588)$} & \multicolumn{2}{|c|}{$\mathrm{MI}(\mathrm{N}=18,331)$} & \multirow[b]{2}{*}{$P$ Value } \\
\hline & $\mathbf{n}$ & $\%$ & $\mathbf{n}$ & $\%$ & $\mathbf{n}$ & $\%$ & $\mathbf{n}$ & $\%$ & \\
\hline T stage & & & & & & & & & $<.001$ \\
\hline $\mathrm{T} 1$ & 474,787 & $65.9 \%$ & 1,369 & $43.6 \%$ & 1,857 & $28.2 \%$ & 4,218 & $23.0 \%$ & \\
\hline $\mathrm{T} 2$ & 203,133 & $28.2 \%$ & 1,000 & $31.8 \%$ & 1,756 & $26.7 \%$ & 3,390 & $18.5 \%$ & \\
\hline T3 & 27,092 & $3.8 \%$ & 484 & $15.4 \%$ & 1,774 & $26.9 \%$ & 1,546 & $8.4 \%$ & \\
\hline $\mathrm{T} 4$ & 2,206 & $0.3 \%$ & 177 & $5.6 \%$ & 737 & $11.2 \%$ & 2,457 & $13.4 \%$ & \\
\hline Unknown & 13,546 & $1.9 \%$ & 112 & $3.6 \%$ & 464 & $7.0 \%$ & 6,720 & $36.7 \%$ & \\
\hline Received ADT & & & & & & & & & $<.001$ \\
\hline No & 548,496 & $76.1 \%$ & 1,025 & $32.6 \%$ & 1,642 & $24.9 \%$ & 5,182 & $28.3 \%$ & \\
\hline Yes & 155,801 & $21.6 \%$ & 2,058 & $65.5 \%$ & 4,781 & $72.6 \%$ & 12,858 & $70.1 \%$ & \\
\hline Unknown & 16,467 & $2.3 \%$ & 59 & $1.9 \%$ & 165 & $2.5 \%$ & 291 & $1.6 \%$ & \\
\hline Locoregional therapy & & & & & & & & & $<.001$ \\
\hline No & 96,803 & $13.4 \%$ & 1,489 & $47.4 \%$ & 2,593 & $39.4 \%$ & 16,379 & $89.4 \%$ & \\
\hline Yes & 623,961 & $86.6 \%$ & 1,653 & $52.6 \%$ & 3,995 & $60.6 \%$ & 1,952 & $10.6 \%$ & \\
\hline
\end{tabular}

Abbreviations: ADT, androgen deprivation therapy; IQR, interquartile range; PSA, prostate-specific antigen.

OS rate of $20.9 \%$, which was significantly worse than those with either very-high-PSA N0M0 disease or N1M0 disease $(P<.001)$.

\section{Effect of Locoregional Treatment}

We also studied the association between locoregional treatment and OS within each subgroup (Table 2 and Figure 3). Among patients with PSA $<98.0 \mathrm{ng} / \mathrm{mL}$ NOM0 disease, a significantly improved 5-year OS rate was seen in those who received locoregional treatment compared with those who did not (91.5\% vs 77.2\%; aHR, 0.44; 95\% CI, $0.43-0.44 ; P<.001)$. Similarly, patients with PSA $\geq 98.0 \mathrm{ng} / \mathrm{mL}$ N0M0 disease had improved survival associated with the receipt of locoregional treatment $(78.9 \%$ vs $38.1 \%$; aHR, 0.28 ; 95\% CI, 0.24-0.34; $P<.001$ ). Among patients with node-positive disease, locoregional treatment was also associated with improved 5 -year OS $(73.7 \%$ vs $46.6 \%$; aHR, 0.44; 95\% CI, 0.40-0.49; $P<.001$ ), although with a smaller effect size than for those with very-high-PSA NOM0 disease $(P<.001)$.

Results of the multivariable Cox regression suggest that patients had increased risk of mortality if they were black, were from counties with a lower household income or education level, were older, had a higher Charlson/Deyo comorbidity score, or had Medicaid/Medicare/other government insurance (Table 2).

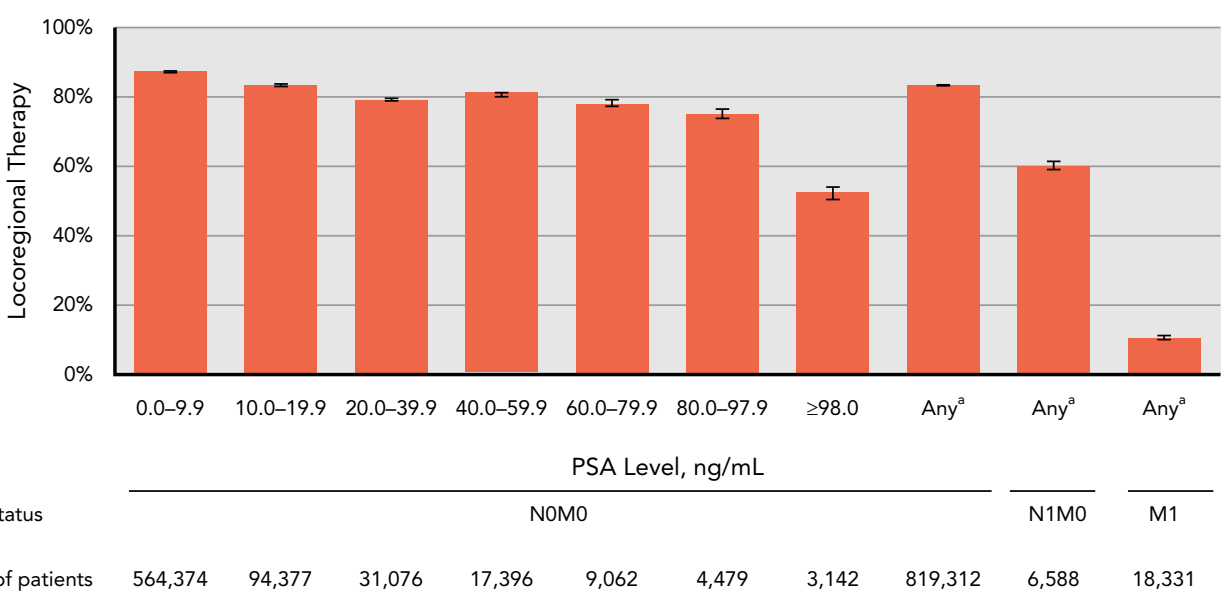

Figure 1. Rates of locoregional treatment among patients with $\mathrm{NOMO}, \mathrm{N} 1 \mathrm{MO}$, or $\mathrm{M} 1$ prostate cancer by PSA level. Error bars indicate $95 \% \mathrm{Cl}$. Abbreviation: PSA, prostate-specific antigen.

alncluded patients that would have had unknown PSA. 
A

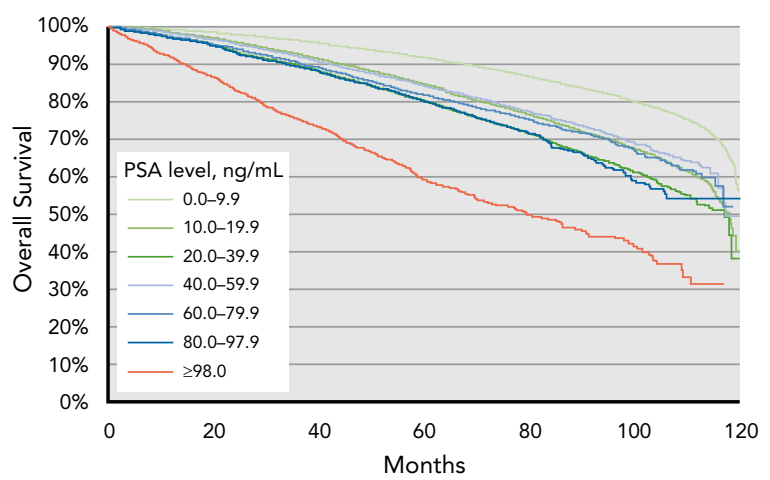

B

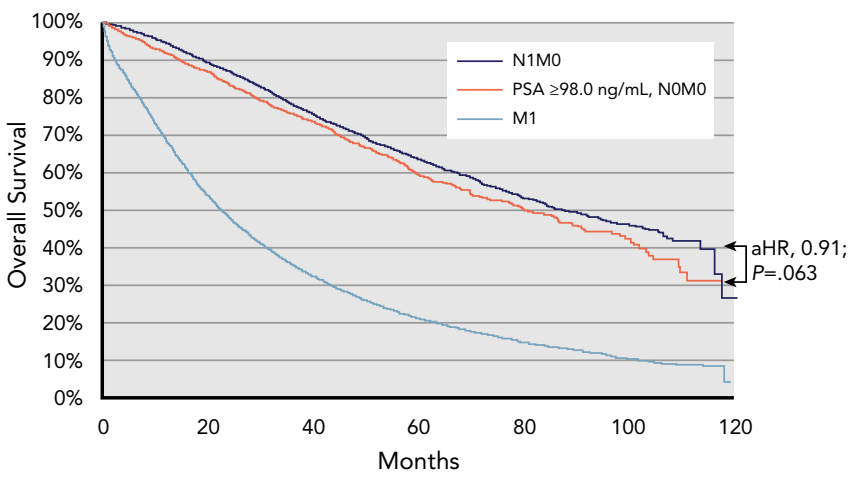

Figure 2. Overall survival among patients with (A) NOMO prostate cancer, stratified by PSA level, and (B) N1M0, very-high-PSA NOM0, or M1 prostate cancer.

Abbreviations: aHR, adjusted hazard ratio; PSA, prostate-specific antigen.

\section{Discussion}

Using a large national cohort of patients, this study determined that those with clinically NOM0 disease and a very high PSA level ( $\geq 98.0 \mathrm{ng} / \mathrm{mL}$ ) had outcomes similar to those of patients with $\mathrm{N} 1$ disease but received definitive locoregional treatment at a lower rate than did patients with lower PSA levels or even those with N1 disease. Receipt of locoregional treatment (prostate/pelvic radiation or radical prostatectomy) was associated with a larger reduction in mortality among those with a very high PSA level and NOM0 disease than among those with lower PSA levels or nodepositive disease, even after adjusting for multiple patientspecific factors, including comorbidity score.

Management of patients with very-high-PSA NOM0 disease is challenging. Imaging may suggest that there is no disease spread beyond the prostate, but the very high PSA level may raise concern about presence of occult metastatic disease. Determining whether a patient is likely to have occult regional nodal or distant metastatic disease is likely to significantly impact treatment decision-making. Multiple randomized trials have shown benefit with locoregional treatment of localized prostate cancer, ${ }^{3,5,6}$ whereas for clinically node-positive disease, data supporting a benefit with locoregional treatment are primarily retrospective in nature..$^{8-13}$ In contrast, for distant metastatic disease, systemic therapy alone is recommended. ${ }^{1}$ These treatment paradigms are reflected in our data, showing high rates $(80 \%-90 \%)$ of locoregional treatment for patients with PSA $<98.0 \mathrm{ng} / \mathrm{mL}$ N0M0 disease, an intermediate rate $(60 \%)$ for those with clinical N1M0 disease, and a low rate $(10 \%)$ for those with M1 disease.

The data showing a lower rate of locoregional treatment $(52.6 \%)$ for patients with very-high-PSA NOM0 disease than for those with lower PSA levels or nodepositive disease suggest that physicians may tend to consider these patients to have occult metastatic disease more frequently than patients with nodepositive disease, resulting in a lower delivery rate of potentially curative treatment. Our data showing high rates of ADT monotherapy among patients with relatively high-PSA NOM0 disease (28.2\%), mirroring the treatment of patients with N1M0 or, to an extent, M1 disease, may also reflect this concern. However, these data also suggest that patients with very-high-PSA NOMO disease have almost identical survival outcomes as those with N1M0 disease, suggesting that they are no more likely to harbor aggressive or occult metastatic disease. Furthermore, the survival benefit associated with locoregional treatment of very-high-PSA NOM0 disease was significantly higher, both in absolute and relative terms, than for N1M0 disease, suggesting that very-high-PSA N0M0 disease may be more curable with locoregional treatment than N1M0 disease, possibly due to a lower burden of gross disease.

Taken together, our data suggest that despite a relatively low rate of locoregional treatment, patients with very-high-PSA NOM0 disease likely have a much better prognosis than those with M1 disease, and a similar or better prognosis than those with N1M0 disease, and should therefore be considered more frequently for definitive locoregional treatment. These data also suggest that patients with a very high PSA level and NOM0 disease by standard imaging modalities (CT and bone scan) may be candidates for pretreatment advanced imaging, such as with PET using tracers $\left(\mathrm{eg},{ }^{18} \mathrm{~F}\right.$-sodium fluoride, ${ }^{18} \mathrm{~F}$-choline, ${ }^{68} \mathrm{Ga}$-prostate-specific membrane antigen, and ${ }^{18} \mathrm{~F}$-fluciclovine). ${ }^{14}$ These advanced imaging modalities, which have been well studied in the posttreatment failure setting, ${ }^{15,16}$ may more clearly delineate which patients have metastatic versus nonmetastatic disease at diagnosis, allowing physicians to more confidently identify candidates for definitive treatment. 
Table 2. Multivariable Regression for Overall Survival

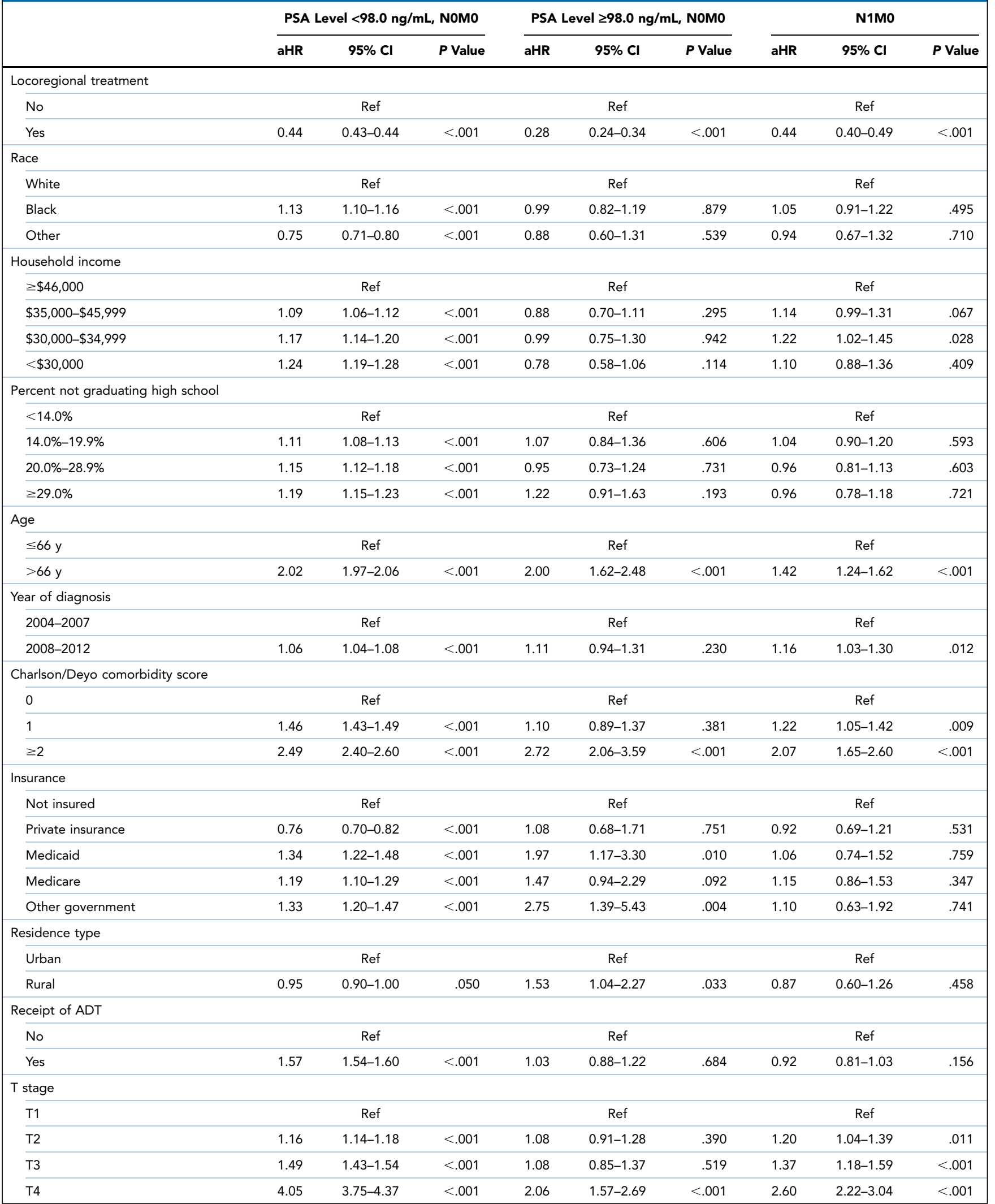

Abbreviations: ADT, androgen deprivation therapy; aHR, adjusted hazard ratio; PSA, prostate-specific antigen. 
A

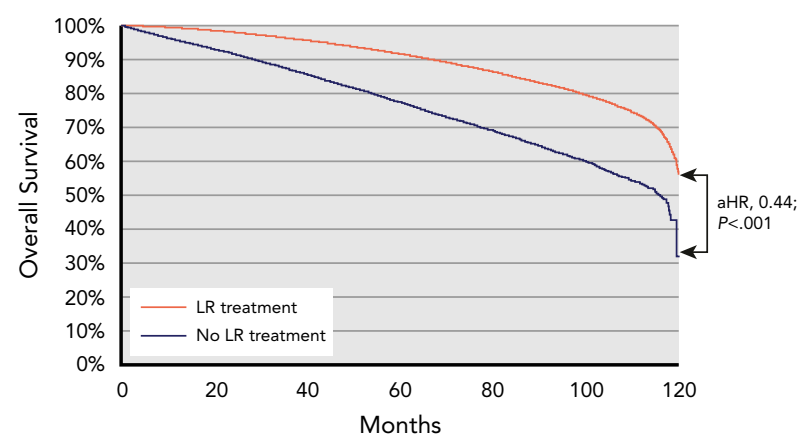

B

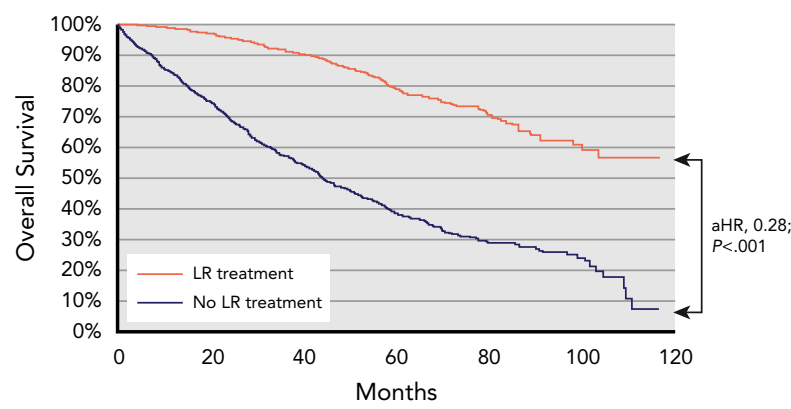

C

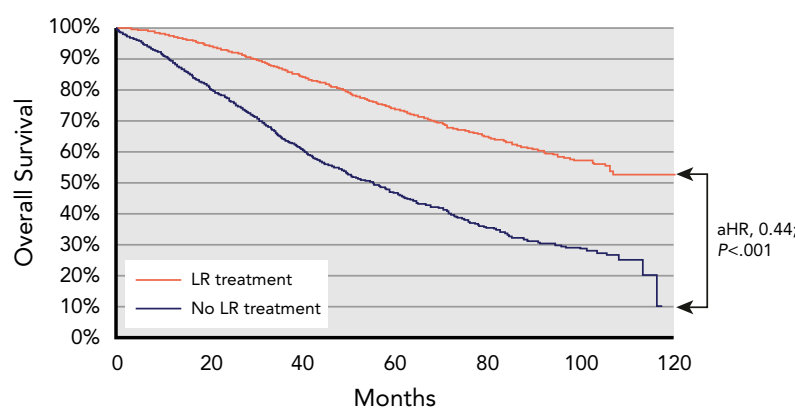

Figure 3. Overall survival by receipt of LR treatment (prostate/pelvic radiation or radical prostatectomy) among patients with (A) PSA $<98.0 \mathrm{ng} / \mathrm{mL}$, NOMO; (B) PSA $\geq 98.0 \mathrm{ng} / \mathrm{mL}$, NOMO; and (C) N1M0 prostate cancer.

Abbreviations: aHR, adjusted hazard ratio; LR, locoregional; PSA, prostatespecific antigen.

Our results are consistent with the work of others ${ }^{17-21}$ showing that, although a very high PSA level portends a poorer prognosis compared with other NOM0 prostate cancer, these presentations may still frequently be curable. Clinical trials establishing the curative role of locoregional treatment and adjuvant hormonal therapy have included men with PSA levels of 50 to $160 \mathrm{ng} / \mathrm{mL},,^{5,22,23}$ although these studies were not designed to determine whether the subpopulation of men with a very high PSA level could benefit from locoregional treatment. A pooled analysis of 2 RTOG trials suggested that patients with a PSA level $\geq 50 \mathrm{ng} / \mathrm{mL}$ have a higher adjusted rate of biochemical failure, distant metastasis, and mortality compared with other high-risk patients, but the effect size was modest, with similar unadjusted rates of 7-year OS compared with those with a PSA level $<50 \mathrm{ng} / \mathrm{mL}$ (64.3\% vs $68.0 \%)$; there was no comparison with a cohort of node-positive patients. ${ }^{17}$ A Canadian registry study showed that among 207 patients with a PSA level $\geq 100 \mathrm{ng} / \mathrm{mL}$, radiation therapy was associated with improved 5-year OS compared with ADT alone $(68 \%$ vs $40 \%) .{ }^{18}$ Several institutional studies have similarly shown good long-term outcomes for patients with very high PSA levels, albeit inferior to outcomes for patients with lower PSA levels. ${ }^{19-21}$ Our study may be the largest to examine treatment patterns or outcomes in patients with very-high-PSA NOM0 disease, allowing us to also adjust for multiple known sociodemographic predictors of treatment receipt and long-term outcomes. ${ }^{10,11,24-28}$

This study must be interpreted with caution in light of several important limitations. First, the data are retrospective, and therefore the results are susceptible to selection bias and confounding. Although we attempted to account for this limitation via use of multivariable analysis, there may be other unmeasured confounders that can explain the practice patterns and survival differences observed. For example, patients with a high PSA at diagnosis may have neglected symptoms or delayed biopsy due to competing medical problems or aversion to definitive therapy for other reasons that were not captured in the database and could not be accounted for in these analyses. These men may also have been more likely to decline definitive therapy. Similarly, our analysis suggesting an association between receipt of locoregional treatment and improved survival could be confounded by important covariates, such as patient performance status or other measures of overall prognosis that are incompletely captured in the Charlson/Deyo comorbidity score.

Second, the NCDB does not contain detailed information regarding how patients were staged. Although patients listed as having Nx or Mx disease were excluded, we did not have information regarding how the regional nodes and distant metastatic sites were evaluated. Based on practice patterns and national guidelines, ${ }^{1,29,30}$ most men with high-risk disease (including those with very high PSA levels) were likely to have had a CT of the abdomen and pelvis and a bone scan. However, it remains possible that some men were miscategorized as having a very high PSA level and N0M0 disease based on incomplete imaging evaluation and incorrect coding of their nodal or distant staging as NO or M0 rather than Nx or Mx, which would have biased these results.

Third, because of limitations in the NCDB, we did not have exact PSA values for levels $>98.0 \mathrm{ng} / \mathrm{mL}$, and therefore these patients had to be grouped for analysis. The population of patients with very-high-PSA NOMO disease is 
likely a heterogeneous group. Therefore, caution must be taken when applying these data, especially for PSA levels much higher than this $98.0 \mathrm{ng} / \mathrm{mL}$ threshold. Future work is needed to validate these data, including prospective studies evaluating the role of locoregional treatment in very-high-PSA NOM0 prostate cancer.

\section{Conclusions}

This study found that patients with N0M0 prostate cancer and a very high PSA level $(\geq 98.0 \mathrm{ng} / \mathrm{mL})$ are less likely to be treated with locoregional treatment compared with those with lower PSA levels or nodepositive disease, despite having similar survival as those with node-positive disease and an even greater survival benefit associated with locoregional treatment. Although management of patients with very-high-PSA
N0M0 prostate cancer remains a challenge, consideration should be given to locoregional treatment, which is an increasing treatment paradigm in the clinically node-positive setting.

Submitted November 9, 2018; accepted for publication February 8, 2019.

Author contributions: Study concept and design: Muralidhar, Nguyen, King, Orio. Data acquisition, analysis, and interpretation: All authors. Statistical analysis: Muralidhar, Nguyen, King, Orio. Drafting of manuscript: All authors. Critical revision of the manuscript for important intellectual content: All authors.

Disclosures: Dr. Nguyen has disclosed that he receives support from Bayer, Astellas, Ferring, Dendreon, Blue Earth, Genome Dx, Augmenix, Boston Scientific, and Janssen. Dr. Efstathiou has disclosed that he is a scientific advisor for Janssen and Blue Earth Diagnostics. The remaining authors have not received any financial consideration from any person or organization to support the preparation, analysis, results, or discussion of this article.

Correspondence: Peter F. Orio III, DO, MS, Department of Radiation Oncology, Brigham and Women's Hospital, 75 Francis Street, Boston, MA 02115. Email: Peter_Orio@dfci.harvard.edu

\section{References}

1. Mohler JL, Lee RJ, Antonarakis ES, et al. NCCN Clinical Practice Guidelines in Oncology: Prostate Cancer. Version 4.2018. To view the most recent version, visit NCCN.org. Accessed October 1, 2018.

2. Pilepich MV, Winter $\mathrm{K}$, Lawton $\mathrm{CA}$, et al. Androgen suppression adjuvant to definitive radiotherapy in prostate carcinoma-long-term results of phase III RTOG 85-31. Int J Radiat Oncol Biol Phys 2005;61:1285-1290.

3. Widmark A, Klepp O, Solberg A, et al. Endocrine treatment, with or without radiotherapy, in locally advanced prostate cancer (SPCG-7/ SFUO-3): an open randomised phase III trial. Lancet 2009;373:301-308.

4. Hamdy FC, Donovan JL, Lane JA, et al. 10-year outcomes after monitoring, surgery, or radiotherapy for localized prostate cancer. N Engl J Med 2016;375:1415-1424.

5. Bolla M, de Reijke TM, Van Tienhoven G, et al. Duration of androgen suppression in the treatment of prostate cancer. N Engl J Med 2009;360: 2516-2527.

6. Bill-Axelson A, Holmberg L, Garmo H, et al. Radical prostatectomy or watchful waiting in early prostate cancer. N Engl J Med 2014;370:932-942.

7. Bilimoria KY, Stewart AK, Winchester DP, et al. The National Cancer Data Base: a powerful initiative to improve cancer care in the United States. Ann Surg Oncol 2008;15:683-690

8. Briganti A, Karnes RJ, Da Pozzo LF, et al. Combination of adjuvant hor monal and radiation therapy significantly prolongs survival of patients with pT2-4 pN+ prostate cancer: results of a matched analysis. Eur Urol 2011 59:832-840

9. Tward JD, Kokeny KE, Shrieve DC. Radiation therapy for clinically nodepositive prostate adenocarcinoma is correlated with improved overall and prostate cancer-specific survival. Pract Radiat Oncol 2013;3:234-240.

10. Rusthoven CG, Carlson JA, Waxweiler TV, et al. The impact of definitive local therapy for lymph node-positive prostate cancer: a populationbased study. Int J Radiat Oncol Biol Phys 2014;88:1064-1073.

11. Lin CC, Gray PJ, Jemal A, et al. Androgen deprivation with or without radiation therapy for clinically node-positive prostate cancer. J Natl Cancer Inst 2015;107:djv119.

12. Ghavamian R, Bergstralh EJ, Blute ML, et al. Radical retropubic prostatectomy plus orchiectomy versus orchiectomy alone for $\mathrm{pTxN}+$ prostate cancer: a matched comparison. J Urol 1999:161:1223-1227; discussion 1227-1228.

13. Engel J, Bastian PJ, Baur H, et al. Survival benefit of radical prostatectomy in lymph node-positive patients with prostate cancer. Eur Urol 2010; 57:754-761.

14. Evans JD, Jethwa KR, Ost P, et al. Prostate cancer-specific PET radiotracers: a review on the clinical utility in recurrent disease. Pract Radiat Oncol 2018;8:28-39.

15. Akin-Akintayo $\bigcirc \bigcirc$, Jani $A B$, Odewole $O$, et al. Change in salvage radiotherapy management based on guidance with FACBC (Fluciclovine) $\mathrm{PET} / \mathrm{CT}$ in postprostatectomy recurrent prostate cancer. Clin Nucl Med 2017:42:e22-28.
16. Byrne K, Eade T, Kneebone A, et al. Delineating sites of failure following post-prostatectomy radiation treatment using 68-Ga-PSMA-PET. Radiother Oncol 2018;126:244-248.

17. Rodrigues $\mathrm{G}$, Bae $\mathrm{K}$, Roach $\mathrm{M}$, et al. Impact of ultrahigh baseline PSA levels on biochemical and clinical outcomes in two Radiation Therapy Oncology Group prostate clinical trials. Int J Radiat Oncol Biol Phys 2011; 80:445-452.

18. Tai P, Tonita J, Woitas C, et al. Treatment outcomes in non-metastatic prostate cancer patients with ultra-high prostate-specific antigen. Int J Radiat Oncol Biol Phys 2012;83:e525-530.

19. Vanasupa BP, Paquette $\mathrm{EL}, \mathrm{Wu} \mathrm{H}$, et al. The role of radical prostatectomy in patients with pretreatment prostate-specific antigen $>$ or $=40 \mathrm{ng} / \mathrm{mL}$. Urol Oncol 2002;7:167-172.

20. Ou YC, Chen JT, Cheng CL, et al. Radical prostatectomy for prostate cancer patients with prostate-specific antigen $>20 \mathrm{ng} / \mathrm{ml}$. Jpn J Clin Oncol 2003;33:574-579.

21. Wiebe $E$, Rodrigues $G$, Lock $M$, et al. Outcome analysis of prostate cancer patients with pre-treatment PSA greater than $50 \mathrm{ng} / \mathrm{ml}$. Can J Urol 2008 15:4078-4083.

22. Bill-Axelson A, Holmberg $L$, Ruutu $M$, et al. Radical prostatectomy versus watchful waiting in early prostate cancer. N Engl J Med 2011;364: 1708-1717.

23. Lawton CAF, Lin X, Hanks GE, et al. Duration of androgen deprivation in locally advanced prostate cancer: long-term update of NRG oncology RTOG 9202. Int J Radiat Oncol Biol Phys 2017;98:296-303.

24. Muralidhar V, Mahal BA, Rose BS, et al. Disparities in the receipt of loca treatment of node-positive prostate cancer. Clin Genitourin Cancer 2017, 15:563-569.

25. McDavid K, Tucker TC, Sloggett A, et al. Cancer survival in Kentucky and health insurance coverage. Arch Intern Med 2003;163:2135-2144.

26. Gilligan T. Social disparities and prostate cancer: mapping the gaps in our knowledge. Cancer Causes Control 2005;16:45-53.

27. Mahal BA, Aizer AA, Ziehr DR, et al. Trends in disparate treatment of African American men with localized prostate cancer across National Comprehensive Cancer Network risk groups. Urology 2014;84:386-392.

28. Mahal BA, Aizer AA, Ziehr DR, et al. The association between insurance status and prostate cancer outcomes: implications for the Affordable Care Act. Prostate Cancer Prostatic Dis 2014;17:273-279.

29. Falchook AD, Salloum RG, Hendrix LH, et al. Use of bone scan during initial prostate cancer workup, downstream procedures, and associated Medicare costs. Int J Radiat Oncol Biol Phys 2014; 89:243-248.

30. Prasad SM, Gu X, Lipsitz SR, et al. Inappropriate utilization of radiographic imaging in men with newly diagnosed prostate cancer in the United States. Cancer 2012;118:1260-1267. 